\title{
Čuječnost kot psihološka intervenca za vsakdanjik
}

\author{
Vita Poštuvan \\ Univerza na Primorskem \\ vita.postuvan@upr.si
}

Naš um v vsakodnevnem življenju pogosto odtava v premlevanje dogodkov, ki so se zgodili v preteklosti, ali načrtuje stvari, ki se bodo šele zgodile. Ker živimo v "stanju avtopilota«, zlahka spregledamo, kaj se resnično dogaja v trenutku tukaj in zdaj. Čuječnost je pristop, ki uči namernega usmerjanja pozornosti v sedanjost, $\mathrm{z}$ namenom sprejemanja, gojenja prijaznosti in sočutja. Korenine pristopa segajo v budistično filozofijo, v okviru psiholoških pristopov pa se čuječnost največkrat povezuje $z$ vedenjsko-kognitivno terapijo v pristop na čuječnosti temelječe kognitivne terapije (М В C T). Pristop M B C T se izkazuje kot eden najučinkovitejših za obvladovanje stresa in depresije. Še posebej to velja za tiste posameznike, katerih vzorci in navade nevede ojačujejo tveganja za remisijo težav.

\section{Izhodišča}

Problem je vplival name, sem pa to tudi pričakovala. Vendar sem ugotovila, da me je bolj potrlo razmišljanje o problemu kot konkretna neugodna situacija, v kateri sem se znašla.

Udeleženka delavnice o čuječnosti, 2016

Pozornost človekovega uma pogosto odtava v premlevanje o dogodkih, ki so se zgodili v preteklosti, ali razmišljanje o tem, kar se šele bo zgodilo. Čuječnost predstavlja usmerjanje pozornosti z namenom in s prijaznostjo v trenutek sedanjosti. Ta usmeritev je koristna, saj na ta način izstopimo iz neozaveščenega življenja, ki mu rečemo tudi »stanje avtopilota«. Na ta način smo pozornejši na različne kvalitete življenja, ki se odvijajo v vsakem trenutku.

Filozofija čuječnosti sicer izhaja iz budistične meditativne prakse, a elemente čuječnosti najdemo tudi v mnogih drugih religijah in filozofskih pristopih, ki temeljijo na introspekciji in gojenju sočutja. Med drugim se najdejo elementi v krščanstvu, islamskih sufijih, židovski kabali . ., široko razširjenost elementov čuječnosti pa verjetno lahko razumemo kot indic, da je čuječnost pravzaprav splošno razširjena človeška vrlina. 


\section{Intervencije, ki temeljijo na čuječnosti}

Med najbolj razširjenimi programi čuječnostnih intervencij sta na čuječnosti temelječe zmanjševanje stresa (Mindfulness-Based Stress Reduction M B S R) in ba čuječnosti temelječa kognitivna terapija (Mindfulness-Based Cognitive Therapy - М В C T) (Teasdale idr., 2000, Segal idr., 2002; 2013). Prvi pristop je pričel razvijati Jon Kabat-Zinn (1994; 1996; 2011), ki je na podlagi lastne meditativne prakse oblikoval program za bolnike s kroničnimi bolečinami. Njegove izkušnje so pokazale, da se je po vključitvi v program spremenil predvsem odnos bolnikov do bolezni, saj sebe niso več doživljali samo kot »bolnike«, temveč kot osebe, pri katerih so kronične bolečine le ena od značilnosti.

Na podlagi teh spoznanj so Segal idr. (2002 in 2013) prilagodili program M B S za namene krepitve duševnega zdravja in vanj vključili več elementov vedenjsko-kognitivne psihoterapije ter ga poimenovali na čuječnosti temelječa kognitivna terapija (Mindfulness-Based Cognitive Therapy - М в С T) (Teasdale idr., 200o; Segal idr., 2013). Tak program je bil sprva namenjen predvsem preprečevanju relapsa po ozdravljeni depresiji in zato so vanj vključevali predvsem ljudi, ki so že okrevali po več epizodah depresije, vendar se jim ta vedno znova vrača. Prve študije so pokazale, da se je odstotek ponovitve depresije po 60 tednih pri vključitvi v program М В С T znižal na $37 \%$ v primerjavi s $66 \%$ pri običajnem zdravljenju (Segal idr., 2002).

Danes se intervencije čuječnosti ne uporabljajo le v preventivne namene, temveč predvsem kot način terapije, terapevtskih pristopov pa je že kar nekaj. Nedavni zaključki metaanalize (Kuyken idr., 2016) so po pregledu 2.555 študij ugotovili pozitiven učinek na izboljšanje depresivne motnje. Znanstvene študije, ki so bile narejene v zadnjih desetletjih, pa skoraj konsistentno kažejo učinke čuječnosti na dobrobit posameznikov tudi pri zmanjševanju stresa in tesnobe, motnjah hranjenja, obsesivno-kompulzivnih motnjah, posttravmatski stresni motnji, kroničnih težavah $\mathrm{v}$ duševnem zdravju ter izboljšanju razpoloženja pri splošni populaciji. Tehnike čuječnosti imajo pozitiven vpliv tudi na telesno funkcioniranje, saj krepijo imunski sistem, ob vadbi se pojavljajo ugodne spremembe v možganskem delovanju, pogosto pa izboljšajo tudi razpoloženje oz. kvaliteto življenja pri bolnikih s kroničnimi bolečinami ali drugimi kroničnimi boleznimi, kot so multipla skleroza, onkološke bolezni itd. (Hempel idr., 2014; Fjorback idr., 2011; Carmody in Baer, 2008).

\section{Kompetence in znanja za uporabo principov čuječnosti}

Psiholog lahko principe čuječnosti uporablja za vzdrževanje lastnega duševnega zdravja in kot terapevtske intervencije za uporabnike svojih sto- 
Preglednica 1 Pregled aktivnosti in ključnih kompetenc ter znanj na področju čuječnosti

\begin{tabular}{ll}
\hline Znanja (iz aktivnosti in vaj) & Kompetence \\
\hline - Teoretična izhodišča čuječnosti & • Poznavanje teoretičnih izhodišč in poosebljanje fi- \\
- Na čuječnosti temelječe psiho- & lozofije čuječnosti \\
loške intervencije - poznavanje, & • Spretnosti vodenja in izvajanja tehnik čuječnosti \\
razumevanje in delovanja & - Doživljanje prijaznosti in sprejemanja situacij brez \\
- Razumevanje pomena spret- & namere po vrednotenju ali izogibanju \\
nosti usmerjanja pozornosti in & • Zavzemanje decentrirane (oddaljene) perspektive \\
gojenja prijaznosti & in opazovanje lastnih misli ter čustev kot zača- \\
- Znanje o pomenu prepoznave & snih, objektivnih dogodkov v umu \\
avt. vzorcev z reflektiranjem & - Zmožnost samoregulacije in konstruktivnega pre- \\
- Način evalviranja ustreznosti in & usmerjanja pozornosti \\
učinkovitosti programov čuječ- & • Zmožnost ocenjevanja in presojanja uporabe raz- \\
nosti & ličnih intervencij \\
\hline
\end{tabular}

ritev. Pri tem poskuša vzpostavljati sprejemajoč odnos do sebe in svojih težav. Kompetence in znanja za delo s čuječnostjo so predstavljene v preglednici 1.

Ena izmed ključnih kompetenc čuječnosti je doživljanje prijaznosti in sprejemanja situacij brez namere po vrednotenju ali izogibanju. Takšno ravnanje pogosto ni enostavno, saj smo kot človeška bitja naravnani, da presojamo situacije, v katerih se znajdemo, pozornost pa usmerjamo predvsem $v$ negativne informacije. Vse to nam je $v$ toku evolucije pomagalo preživeti kot vrsti, vendar nam $\mathrm{v}$ današnjem času včasih povzroča celo več preglavic kot dobrobiti. Spodnje aktivnosti lahko pomagajo razvijati opisane kompetence in znanja.

\section{Usmerjanje pozornosti $v$ prijaznost}

Usmerjanja pozornosti se lahko namenoma učimo. Ena izmed možnosti je ta, da v vsakdanjiku ne spregledamo pozitivnih dnevnih dogodkov. Lahko si pomagamo $\mathrm{z}$ vajo naključnih dobrih drobnih del.

\section{Aktivnost: Naključna dobra dela}

Skozi razmik enega tedna vsak dan izvedite naključno drobno dobro delo. Priporoča se, da dela niso vezana na isti kontekst, ampak o njih razmislite in jih usmerite predvsem $\mathrm{v}$ tista področja vašega življenja, kjer ste takšnih drobnih dobrih del redkeje vajeni. Pri izvajanju ste lahko ustvarjalni in fleksibilni. Lahko so drobna dobra dela naključna, lahko jih načrtujete vnaprej.

Če bi imeli z izvedbo vaj težave, lahko slednje nekoliko prilagodite: npr. izvedete dobra dela sami zase, si jih samo zamislite. Te prilagoditve opišite 
Preglednica 2 Beležnica drobnih dobrih del

\begin{tabular}{|c|c|c|c|c|}
\hline $\begin{array}{l}\text { Za katero izku- } \\
\text { šnjo je šlo? }\end{array}$ & $\begin{array}{l}\text { Kakšni so bili } \\
\text { vaši telesni ob- } \\
\text { čutki med to iz- } \\
\text { kušnjo (opišite } \\
\text { podrobno)? }\end{array}$ & $\begin{array}{l}\text { Katera razpolo- } \\
\text { ženja in čustva } \\
\text { so spremljala } \\
\text { dogodek? }\end{array}$ & $\begin{array}{l}\text { Katera misli so } \\
\text { bile prisotne ob } \\
\text { dogodku? }\end{array}$ & $\begin{array}{l}\text { Katere misli se } \\
\text { vam porajajo } \\
\text { zdaj, ko to pi- } \\
\text { šete? Koliko ste } \\
\text { se zavedali iz- } \\
\text { kušnje, ko se je } \\
\text { dogajala? }\end{array}$ \\
\hline $\begin{array}{l}\text { Na poti domov } \\
\text { sem pomagal } \\
\text { sosedi nesti } \\
\text { torbo. }\end{array}$ & $\begin{array}{l}\text { Občutek vetra } \\
\text { na obrazu, zave- } \\
\text { danje napetosti } \\
\text { v rokah in ra- } \\
\text { menih, dvig ko- } \\
\text { tičkov ustnic. }\end{array}$ & $\begin{array}{l}\text { Sproščenost, } \\
\text { ugodje. }\end{array}$ & $\begin{array}{l}\text { "Sosedi je bilo } \\
\text { lažje.«»Prav } \\
\text { prijetno je biti } \\
\text { malo dlje na } \\
\text { zraku.» }\end{array}$ & $\begin{array}{l}\text { „Taka malen- } \\
\text { kost, a sem } \\
\text { vesel/-a, da sem } \\
\text { jo naredil/-a." }\end{array}$ \\
\hline
\end{tabular}

v refleksiji in razmislite, kako bi lahko naslednjič stvari še izboljšali. Vsa dobra dela beležite $\mathrm{v}$ obliki beležnice.

Beležnico prenesite $\mathrm{v}$ zvezek ali drug način zapisa in dodajte vrstice $\mathrm{z}$ datumi za vsak zapis. Po celem tednu napišite kratko refleksijo doživljanja:

- Kako ste doživeli vajo?

- Katera drobna dobra dela ste izvedli? Kako je izgledal potek vaših del?

- Ste si dobra dela vnaprej zamislili ali ste jih spontano priklicali v situacijah?

- Kakšen je bil odziv drugih? Opišite, kako so variirale reakcije.

- Kako je vaja vplivala na vas? Opišite, kako so variirala vaša občutenja med tednom.

- Kaj vas je presenetilo pri izvajanju?

- Kaj je bilo težko? Ali vedno zmoremo delati »za druge«?

- Pomislite na svoje razpoloženje in izvajanje vaje. Kdaj je bilo drobna dobra dela lažje izvesti: takrat, ko ste bili dobre ali slabe volje? Kako si razlagate svoje odzive?

- Kaj ste začutili pri sebi, kar je vredno vzdrževati tudi naprej?

Ob tej vaji pogosto doživljamo pozitivna čustva. Vaja pomaga ozavestiti, koliko drobnih dobrih trenutkov v življenju nasploh že obstaja, ki jih pogosto spregledamo, hkrati pa daje priložnost, da z izvedbo drobnih dobrih del tudi sami prispevamo h gojenju vrednot prijaznosti.

Pogosto vajo lažje izvajamo takrat, ko smo dobro razpoloženi. Vendar izkušnje kažejo, da lahko z izvajanjem dobrih del vplivamo na počutje in ga na ta način izboljšamo. 


\section{Življenje na avtopilotu}

Med najpreprostejšimi vajami čuječnosti je vaja $z$ rozino. Uči nas drugačnega pogleda na vsakdanje stvari, aktivnosti in navade. Namen vaje je med drugim ozavestiti pomen pozornosti za naše počutje in sodelovanja vseh čutov v zaznavanju.

\section{Aktivnost: Poskusimo rozino}

Za demonstracijo, kako deluje naše zaznavanje, bomo naredili preprosto vajo. Poskusili bomo opazovati predmet brez presojanja, brez posebnega namena. Poskusite si dovoliti, da boste naslednje minute uporabili kot eksperiment sebi.

Pri vaji uporabite rozino, lahko pa si omislite tudi kakšen drug predmetek, s katerim se lahko poigrate. Nobenega razloga ni, da mora biti to kaj posebnega. Prav nasprotno: raje izberite kakšno reč, ki vam je popolnoma vsakdanja in bi ravno zato bila dober primer poigravanja s pozornostjo.

Vzemite rozino (ali drug predmet) v vašo dlan. Osredotočite se nanjo (nanj). Predstavljajte si, da ste ravno padli z Marsa na Zemljo in ta predmet vidite prvič v življenju. Vzemite si čas in zelo podrobno preučite rozino. Poskusite ji posvetiti vso vašo pozornost. Če vam bodo med vajo misli odtavale v razmišljanje o tem, kaj počnete, poskusite to zaznati in vedno znova in znova misli vrniti v preprosto opazovanje različnih kvalitet predmetka pred vami ter trenutka sedanjosti, v katerem živite.

Naj vaše oči pregledajo vsak del predmetka; poglejte, kateri deli so svetlejši, kateri temnejši. Kakšne barve so izbočeni in kakšne vbočeni deli? Kako izgledajo vsi deli predmeta, kakšne so asimetrične oblike?

Primite predmetek med palec in kazalec. Dotaknite se njegove površine, obračajte ga med prsti. Če vam ustreza, lahko zaprete oči; to poveča vaše zaznavanje dotika.

Poskusite biti radovedni v procesu raziskovanja predmeta. Ponesite ga $\mathrm{k}$ ušesom in poskusite slišati zvoke okoli njega. Morda lahko predmet tudi malo podrgnete, ga stisnete ali zmečkate in pri tem opazujte, kako se spreminjajo zvoki.

Podržite predmet pod nosnicami in z vsakim vdihom zajemite vse vonje, arome ali odtenke, ki so prisotni. Poskusite zaznati, kaj se ob tem dogaja v vas, ali je kakšen zanimiv občutek $v$ vaših ustih ali želodcu.

Sedaj nesite rozino v bližino ustnic, pri čemer bodite pozorni, kako roke in dlani točno vedo, kako to storiti in kam položiti rozino. Poigrajte se s spodnjo ustnico - kako je rozino čutiti tam?

Položite rozino v usta, ne da bi jo žvečili. Bodite pozorni, kako jo vstavite 
v usta. Nekaj trenutkov raziskujte občutke v vaših ustih, raziskujte rozino $\mathrm{z}$ vašim jezikom.

Ko ste pripravljeni, pričnite rozino žvečiti. Bodite pozorni na to, kako in kje jo morate prežvečiti - in kje v ustih to počnete. Zelo zavestno naredite prvih nekaj grižljajev in opazujte, kaj se ob tem zgodi. Občutite, kako poteka okušanje, tudi ko nadaljujete z žvečenjem. Ne da bi rozino pogoltnili, poskusite zaznati okus in teksturo $v$ ustih in kako se ta spreminja skozi čas ter kako se trenutek za trenutkom spreminja tudi sama rozina.

Ko ste pripravljeni, pogoltnite rozino - poskusite uvideti, kje se prične priprava tega procesa, tako da ga lahko zavestno opazujete.

Končno poskusite občutiti, kaj ostane od rozine, ko se premika po požiralniku v želodec. Kako se odziva telo na ta proces? Poskusite zaznati, kaj se dogaja v želodcu, v ustih.

Če imate še eno rozino, lahko vajo ponovite.

Refleksija

- Kako ste se počutili?

- Je bilo kaj nenavadnega?

- Kako vam je bila vaja všeč?

- Kakšen bi lahko bil pomen te vaje?

Čuječnost ni to, da smo pozornejši na nekaj, temveč da smo pozorni drugače in smiselneje $-z$ vsemi čuti, $z$ vsem telesom. Vaja $z$ rozino nam pove, kaj v vsakodnevnem življenju izpuščamo iz naših izkušenj (npr. katere senzorne informacije prezremo, nismo pozorni nanje).

Pogosto nam med to vajo misli bežijo sem in tja. Morda tudi premišljujemo, zakaj neki vajo izvajamo. Ravno zaradi teh procesov pogosto ne doživljamo trenutkov tako polno, kot bi jih lahko. Rečemo tudi, da ne živimo v danem trenutku, vendar je med vajo vedno znova priložnost, da se k neobsojajočemu opazovanju vrnemo. Življenje na avtopilotu lahko izklopimo s tem, da naredimo stvari čuječe.

\section{Zaključek}

Izkušnjo drugačne izkušnje hranjenja, poslušanja, opazovanja lahko prenesemo na vplivanje tega na naše razpoloženje. Kadar smo slabe volje, se pogosto negativno vrednotimo. S čuječim pristopom se lahko oddaljimo od tega, da slabo voljo vidimo kot nekaj stalnega, nespremenljivega, kot središče naših težav, in se hkrati zavedamo, da lahko do slabe volje pristopimo brez pričakovanj, lahko se oddaljimo od misli in čustev podobno, kot 
smo se oddaljili od prehranjevanja. Slaba volja tako postane samo trenutek, ki ga doživljamo kot žalostnega - nismo pa mi žalostni. Živeti v tem trenutku pomeni videti svoje misli in čustva kot dogodke, ki bodo minili. To je podobno, kot minejo tudi zvoki, vidne zaznave, vonji, okusi, dotiki. S tem ko se zavedamo minljivosti, lahko povečamo tudi občutek hvaležnosti za dane izkušnje.

\section{Literatura}

Carmody, J. in Baer, R. A. (2008). Relationships between mindfulness practice and levels of mindfulness, medical and psychological symptoms and well-being in a mindfulness-based stress reduction program. The Journal of Behavioral Medicine, 31(1), 23-33.

Fjorback, L. O., Arendt, M., Ornbol, E., Fink, P., in Walach, H. (2011). Mindfulness-based stress reduction and mindfulness-based cognitive therapy: A systematic review of randomized controlled trials. Acta Psychiatrica Scandinavica, 124(2), 102-119

Hempel, S.,Taylor, S. L., Marshall, N. J., Miake-Lye, B. A., Beroes, J. M., Shanman, R., Solloway, R. M., in Shekelle, P. G. (2014). Evidence map of mindfulness. Department of Veterans Affairs.

Kabat-Zinn, J. (1994). Wherever you go, there you are: Mindfulness meditation in everyday life. Hyperion Books.

Kabat-Zinn, J. (1996). Full catastrophe living. Piatkus.

Kabat-Zinn, J. (2011). Kamorkoli greš, si že tam: z meditacijo iz spanca avtomatizma v vsakdanjem življenju. Iskanja.

Kuyken, W., Warren, F. C., Taylor, R., Whalley, B., Crane, C., Bondolfi, G., Hayes, R., Huijbers, M., Ma, H., Schweizer, S., Segal, Z., Speckens, A., Teasdale, J., Heeringen, K., Williams, M., Byford, S., Byng, R., in Dalgleish, T. (2016). Efficacy of mindfulness-based cognitive therapy in prevention of depressive relapse: An individual patient data meta-analysis from randomized trials. JAMA Psychiatry, 73(6), 565-574.

Segal, Z., Williams, M., in Teasdale, J. (2002). Mindfulness-based cognitive therapy for depression. The Guilford Press.

Segal, Z., Williams, M., in Teasdale, J. (2013). Mindfulness-based cognitive therapy for depression. The Guilford Press.

Teasdale, J. D., Segal, Z. V., Williams, J. M. G., Ridgeway, V. A., Soulsby, J. M., in Lau M. A. (2000). Prevention of relapse/recurrence in major depression by mindfulness-based cognitive therapy. Journal of Consulting and Clinical Psychology, 68(4), 615-623.

\section{Mindfulness As a Psychological Intervention for the Everyday}

Our minds have a tendency to wander into rumination and overthinking of the events that have already happened in the past or are planning events, 
that will happen in the future. Because we live in an autopilot state, we easily slip into not recognising the events that are happening here and now. Mindfulness is an approach that aims to focus our intention into the present moment, with the intention of acceptance, kindness and compassion towards the experience. The roots of the mindfulness can be found in Buddhist philosophy. In psychology the mindfulness-based cognitive therapy ( one of the most recognised interventions. It has been proven to efficiently manage signs of stress and depression, specially with people with the higher risk of remission. 